\title{
EFFECTS OF IN VITRO PLANT AGES ON THE SUBSEQUENT GROWTH OF Plumbago indica L. AFTER EX VITRO TRANSPLANTATION
}

\author{
Tran Tu Khoa ${ }^{1}$, Pham Minh Duy ${ }^{2}$, Tran Thi Huong ${ }^{3}$, Nguyen Thi Quynh ${ }^{2, *}$ \\ ${ }^{1}$ VNUHCM-University of Science, Ho Chi Minh City \\ ${ }^{2}$ Institute of Tropical Biology, VAST \\ ${ }^{3}$ Tay Nguyen University, Dak Lak Province
}

Received 10 December 2020, accepted 16 March 2021

\begin{abstract}
The Indian leadwort (Plumbago indica L.) of the family Plumbaginaceae is a plant with high pharmaceutical value, as it contains plumbagin, a naphthoquinone with antibacterial, antifungal and anticancer properties. Among the propagation methods for the Indian leadwort, in vitro propagation is considered an effective method in producing disease-free transplants in a short period of time with high propagation rate. When plants grown in vitro are transferred to ex vitro condition, the environmental factors in the nursery house such as light, temperature, humidity and microorganism in the soil will affect their growth. Characteristics of transplants themselves is also critical for the subsequent growth. It is, thus, essential to establish the standards to evaluate and qualify in vitro plants for transplanting to ex vitro condition. Among these standards, the culture age of in vitro plants affects the maturations of their root, stem and leaves, which can in turn influence the acclimating ability and growth of in vitro plants after transplantation. The purpose of this study is to investigate the effects of the culture age of in vitro Indian leadwort plants on their performance during ex vitro stage. For this purpose, three different culture ages of uniform in vitro plants, 35, 42 and 49 day-old, were studied. After 28 days of cultivation in the nursery house under the light intensity of $70 \pm 10 \mu \mathrm{mol} \mathrm{m}^{-2} \mathrm{~s}^{-1}$, temperature of $35 \pm 4{ }^{\circ} \mathrm{C}$ and relative humidity (RH) of $60 \pm 10 \%$, all three treatments achieved $100 \%$ survival rate. Increased fresh and dry weights and percentage of dry matter after cultivation in ex vitro condition were not statistically different between 42 day-old and 49 day-old in vitro plants, but were significantly different between these plants and 35 day-old in vitro plants. The development of shoot and root in ex vitro stage of 42 day-old and 49 day-old in vitro plants was more balanced, as shown by the higher ratio of shoot/root dry weight, than 35 day-old in vitro plants. The results of this study showed that for this Plumbago species, bigger in vitro plants led to better growth during ex vitro stage. These results also indicated that it was possible to transfer in vitro Plumbago plants to ex vitro condition after 5 weeks of in vitro culture stage.
\end{abstract}

Keywords: Plumbago indica, ex vitro, in vitro, plant propogation, survival rate.

Citation: Tran Tu Khoa, Pham Minh Duy, Tran Thi Huong, Nguyen Thi Quynh, 2021. Effects of in vitro plant ages on the subsequent growth of Plumbago indica L. after ex vitro transplantation. Academia Journal of Biology, 43(1): 109-118. https://doi.org/10.15625/2615-9023/15798

*Corresponding author email: qtnguyen_vn@yahoo.com

(O2021 Vietnam Academy of Science and Technology (VAST) 


\section{INTRODUCTION}

Indian leadwort (Plumbago indica L.), known as "Xích hoa xà" in Vietnamese, a plant of the family Plumbaginaceae, originates from India and South East Asian countries (Do et al., 2004). It is known that this species has the highest content of plumbagin (5hydroxy-2-methyl-1, 4-naphthoquinone) (Mallavadhani et al., 2002). Plumbagin is found mainly in the root, but is also produced in the stem and leaves of the Indian leadwort ( Galal et al., 2013; Mallavadhani et al., 2002). Many studies showed that plumbagin has cell proliferation inhibition (Panichayupakaranant et al., 2002), anticancer (Jamal et al., 2014), antifungal and antibacterial properties (Sumathy et al., 2011). Indian leadwort plant can be propagated by tubers (tuberous roots), or cuttings with the assistance of plant growth regulators (Jose et al., 2014). However, these methods require long propagation time with low multiplication rate (Pant et al., 2012). In vitro propagation has been used as a more efficient method than the conventional propagation to produce a large number of disease-free, uniform and genetically stable plants within a short period of time without dependence on weather condition and season (Chandra et al., 2010). A few studies on in vitro propagation of Indian leadwort through direct organogenesis or callus induction and regeneration using stem, leaf or root segments have been conducted (Bhadra et al., 2009; Priyanjani et al., 2019). However, when transferred to ex vitro condition, the survival rate of the in vitro plants was very low, only about $25 \%$, mostly due to the difference of the environmental conditions of the nursery house (low humidity and higher temperature) compared to in vitro conditions, and the presence of microorganisms in the root environment during the initial acclimation period (Priyanjani et al., 2019). In vitro plants, when transferred to ex vitro condition (greenhouse or plastic covered nursery house), have to cope with considerable changes in environmental factors, including temperature, humidity, light intensity, etc., as well as biological factors, including the activity of the photosystem and the presence of microorganisms in the soil (Deb \& Imchen, 2010). The sudden changes in living conditions can increase transpiration and weaken the plants, leading to low survival rate and slow growth in the nursery house, affecting plant production cost and the application of micropropagation in transplant production (Pospíšilová et al., 2007). Many studies tried to increase in vitro plant aclimation ability during transplanting to $e x$ vitro condition by controlling ex vitro environmental factors, improving in vitro culture condition, etc. Some studies aimed at controlling the opening and closing of stomata, investigating the changes in chloroplast structure and metabolism of in vitro plants after transplanting to ex vitro condition (Bolar et al., 1998; Pospíśilová et al., 2007). However, few studies have investigated the suitable age of in vitro plants at which they can withstand the changes in living environment when transferred to ex vitro condition. The age of in vitro plants indicates the maturation in function of shoot and root, and also affects the growth and development of plants under partially or completely controlled environment in the nursery. Thus, it is essential to identify the suitable age of in vitro Indian leadwort plants for transplanting to ex vitro condition. Not only does it provide more insights into adaptation of growth and development of Indian leadwort plants during transition from in vitro to ex vitro condition, it also helps to establish an important step in the procedure for micropropagation of Indian leadwort, offering significant economic benefits when applied to practical production.

\section{MATERIALS AND METHODS}

Plant materials used in this experiment were in vitro Indian leadwort plants, originating from Yok Don National Park (Dak Lak Province, Vietnam). The in vitro plants were cultured on MS macro-and micro-nutrient solution (Murashige and Skoog, 1962), supplemented with $10 \mathrm{~g} \mathrm{~L}^{-1}$ sucrose (Bien Hoa Sugar Co., Dong Nai Province, Vietnam), 
$7 \mathrm{~g} \mathrm{~L}^{-1}$ agar (Ha Long Food Co., Hai Phong Province, Vietnam) and Morel \& Wetmore vitamin solution (Morel \& Wetmore, 1951), in plastic bag-type vessels $(\mathrm{V}=1 \mathrm{~L}$ when inflated with air) having two ventilated paper filter discs (Nguyen et al., 2016). Each vessel contained 6 shoots having two open leaves with $100 \mathrm{~mL}$ culture solution. The plants were cultured under photosynthetic photon flux density (PPFD) of $35 \pm 5 \mu \mathrm{mol} \mathrm{m} \mathrm{m}^{-2} \mathrm{~s}^{-1}$, provided by white fluorescent lamps (Dien Quang Co., Ho Chi Minh City, Vietnam), with photoperiod of $12 \mathrm{~h} /$ day, air temperature of 25 $\pm 2{ }^{\circ} \mathrm{C}$, relative humidity (RH) of $55 \pm 5 \%$. PPFD was measured with a LI-250A light meter coupled with a LI-190R quantum sensor (LI-COR® Inc., Lincoln, USA).

Ten each of three different in vitro culture ages of Indian leadwort plants, 35, 42 or 49 day-old at the time of transplant and having an average of 4, 5 and 6 leaves, respectively, were taken out from culture bags on the same day, and the experiment was replicated three times. Average initial fresh weights of 35,42 and 49 day-old plants were 320,800 and $950 \mathrm{mg}$ per plant, respectively, and the average initial dry weights were $35.5,70.1$ and $85.6 \mathrm{mg}$, respectively. The roots were washed clean under running tap-water to remove agar, then the plants were quickly transplanted into plastic pots $(\varnothing=8 \mathrm{~cm}$, height $=13 \mathrm{~cm})$ containing Klasmann growing substrate (Klasmann-Deilmann $\mathrm{GmbH}$, Geeste, Germany) mixed with perlite (Cell Green Co., Binh Duong province, Vietnam) at the ratio of 5:1, and put in nursery house with daily average PPFD of $70 \pm 10 \mu \mathrm{mol} \mathrm{m} \mathrm{m}^{-2} \mathrm{~s}^{-1}$, average temperature of $35 \pm 4{ }^{\circ} \mathrm{C}$, average $\mathrm{RH}$ of $60 \pm 10 \%$. During the first four days after transplanting, the humidity around the plants were maintained by a Faran humidifier (Faran Industrial Co., Ltd., Gyeonggi-do, South Korea). From the fifth day onward, the plants were watered three times/day (total $200 \mathrm{~mL} /$ day per plant) using a drip irrigation system (Netafim, Tel-Aviv, Israel). From the eighth day onward, the plants were fertilized with dissolved NovAcid fertilizer (19-19-19,
$\mathrm{EC}=1.0 \mathrm{dS} \mathrm{m} \mathrm{m}^{-1}, \mathrm{pH}=5.5-6.5$ ) (Israel Chemicals Ltd., Tel-Aviv, Israel), applied through the drip irrigation 3 times/week.

On days 14 and 28 after transplantation, the growth parameters of the plants were measured, including survival rate, fresh (FW) and dry weights (DW), number of leaves (NoL), shoot length, root length and leaf area (LA) (measured using a LI-3100C area meter, LICOR® Inc., Lincoln, USA). The bioassays for ascertaining relative activity of endogenous hormones (auxin and cytokinin) in Indian leadwort plants were carried out on day 28 according to the method developed by Nguyen et al. (2003). Increased fresh and dry weights (IFW, IDW) of plants was calculated by deducting average initial fresh and dry weights from the fresh and dry weights measured on days 14 and 28. Percentage of dry matter (\% DM) was a proportion of dry weight to fresh weight measured on days 14 and 28. Relative growth rate (RGR) was calculated based on the equation of Hoffmann \& Poorter (2002):

$$
\mathrm{RGR}=\frac{\overline{\ln \mathrm{W}_{2}}-\overline{\ln \mathrm{W}_{1}}}{\mathrm{t}_{2}-\mathrm{t}_{1}}
$$

In which $\mathrm{W}_{1}$ and $\mathrm{W}_{2}$ were dry weights of Indian leadwort plants at time $t_{1}$ and $t_{2}$ (day), with $t_{2}>t_{1}$.

One-way ANOVA test was performed on the data using STATGRAPHICS Plus 3.0 software for Windows. For parameters with significant differences among treatments, means of three treatments were ranked by least significant difference (LSD) test at $\mathrm{p} \leq 0.05,0.01$ or 0.001 . Graphs were made with Microsoft Excel 2019.

\section{RESULTS AND DISCUSSION}

In vitro Indian leadwort plants had, regardless of the culture ages, $100 \%$ survival rate 14 and 28 days after transplantation to ex vitro condition, and increased in biomass while culturing in the nursery house (Fig. 1, Table 1).

The difference in age of in vitro plants was reflected to the differences of the weight and 
NoL of the plants at the time of transplantation. These differences could influence the ability to absorb sun light by the leaves for photosynthesis and nutrients in the soil by the roots for the metabolic processes necessary for the growth of the plants. Besides, the difference in NoL affects the total amounts of light and $\mathrm{CO}_{2}$ captured for photosynthesis (Donnelly et al., 1985). D35 old plants had the lowest IFW, IDW, NoL and LA compared to the other two ages (Table 1, Fig. 2).

According to Weraduwage et al. (2015), the relationship between growth and leaf development is not linear. It depends on the distribution of carbohydrates between leaves and roots. Root development is related to water and nutrient absorption, and, as a result, affects the photosynthetic rate of plants, especially the activity of photosystem II (Zakaria et al., 2020). Therefore, IFW, IDW and NoL of D42 and D49 plants were not significantly different on both day 14 and day 28 after transplantation. LA of D49 plants was wider $\left(46.5 \mathrm{~cm}^{2}\right)$ than that of D35 and D42 plants on day 14 day after transplantation. However, 28 days after transplantation, LA $\left(71.8 \mathrm{~cm}^{2}\right)$ of D49 plants was lower than that $\left(74.1 \mathrm{~cm}^{2}\right)$ of D42 plants (Table 1).

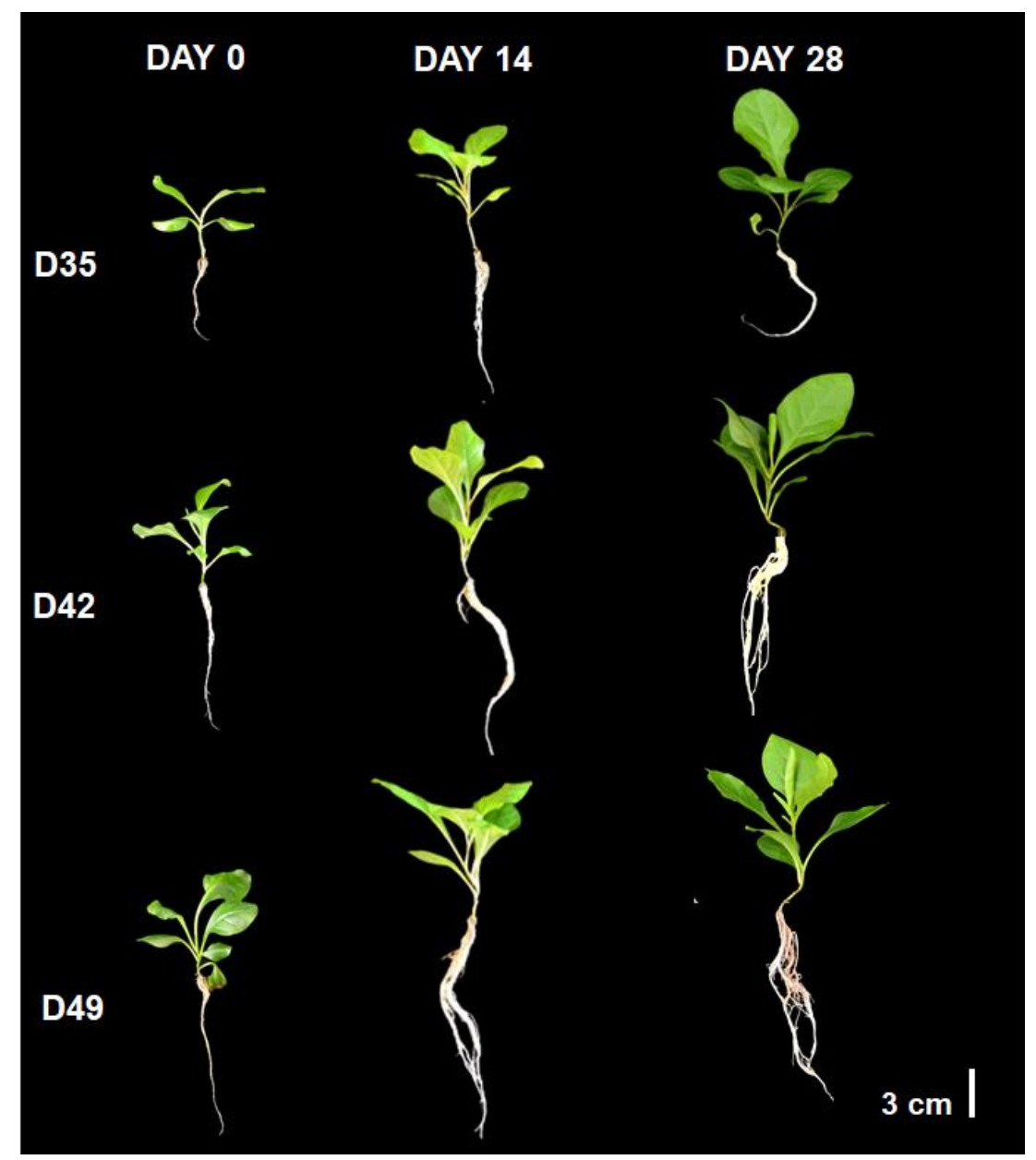

Figure 1. Growth of in vitro Plumbago indica L. plants of different ages 14 and 28 days after transplantation into ex vitro stage in the nursery house.

Notes: For the age codes, D35, D42 and D49 refer to the ages (days) of in vitro plants at the time of transfer to the ex vitro stage. 
Table 1. The increases of fresh weight (IFW) and dry weight (IDW), number of leaves (NoL) and leaf area (LA) of in vitro Plumbago plants 14 (D14) and 28 (D28) days after transplantation to ex vitro condition

\begin{tabular}{|c|c|c|c|c|c|c|c|c|}
\hline \multirow{2}{*}{ Age $^{\mathrm{z}}$} & \multicolumn{2}{|c|}{ IFW (m/plant) } & \multicolumn{2}{c|}{ IDW (mg/plant) } & \multicolumn{2}{c|}{ NoL (leaves/plant) } & \multicolumn{2}{c|}{ LA $\left(\mathrm{cm}^{2}\right)$} \\
\cline { 2 - 9 } & D14 & D28 & D14 & D28 & D14 & D28 & D14 & D28 \\
\hline D35 & $259.3 \mathrm{~b}^{\mathrm{w}}$ & $795.6 \mathrm{~b}$ & $55.1 \mathrm{~b}$ & $105.7 \mathrm{~b}$ & $5.4 \mathrm{~b}$ & $6.3 \mathrm{~b}$ & $21.9 \mathrm{c}$ & $33.6 \mathrm{c}$ \\
\hline $\mathrm{D} 42$ & $546.2 \mathrm{a}$ & $1601.9 \mathrm{a}$ & $142.9 \mathrm{a}$ & $245.0 \mathrm{a}$ & $6.2 \mathrm{a}$ & $7.9 \mathrm{ab}$ & $41.2 \mathrm{~b}$ & $74.1 \mathrm{a}$ \\
\hline D49 & $516.8 \mathrm{a}$ & $1548.8 \mathrm{a}$ & $152.1 \mathrm{a}$ & $252.5 \mathrm{a}$ & $6.6 \mathrm{a}$ & $8.8 \mathrm{a}$ & $46.5 \mathrm{a}$ & $71.8 \mathrm{~b}$ \\
\hline ANOVA $^{\mathrm{x}}$ & $* * *$ & $* * *$ & $* * *$ & $* * *$ & $*$ & $* *$ & $* * *$ & $* * *$ \\
\hline CV $(\%)^{2}$ & 2.5 & 1.3 & 4.5 & 1.3 & 6.0 & 6.3 & 2.8 & 0.6 \\
\hline
\end{tabular}

Notes: ${ }^{\mathrm{z}}$ : For the age codes, see Fig. 1 ; ${ }^{\mathrm{y}}$ : Abbreviations of D14 and D28 refer to measuring days; ${ }^{\mathrm{x}}$ : ${ }^{*},{ }^{*}$, or ${ }^{* * *}$ : Significant at $\mathrm{p} \leq 0.05,0.01$ or 0.001 respectively; ${ }^{\mathrm{w}}$ : Means in the same column followed by the same letters are not significantly different according to LSD-test.

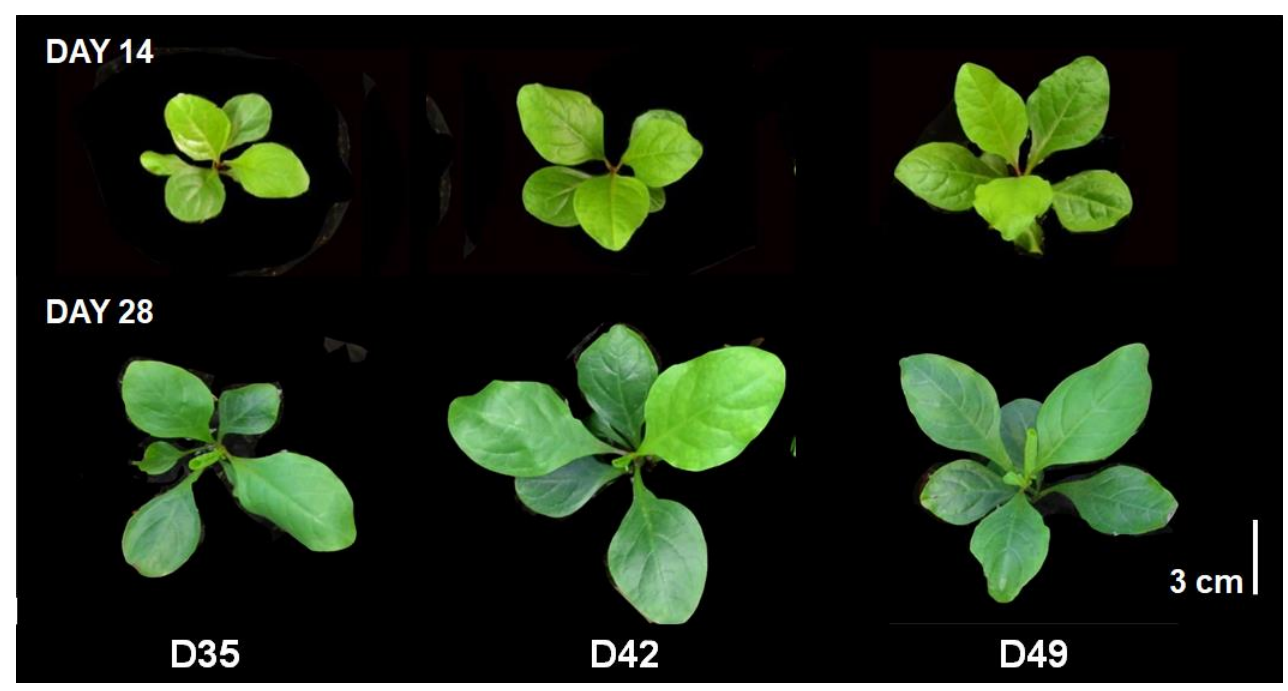

Figure 2. Leaf canopy of in vitro Plumbago plants 14 (upper) and 28 (lower) days after transplantation to the ex vitro condition in the nursery house Notes: For the age codes, see Fig. 1.
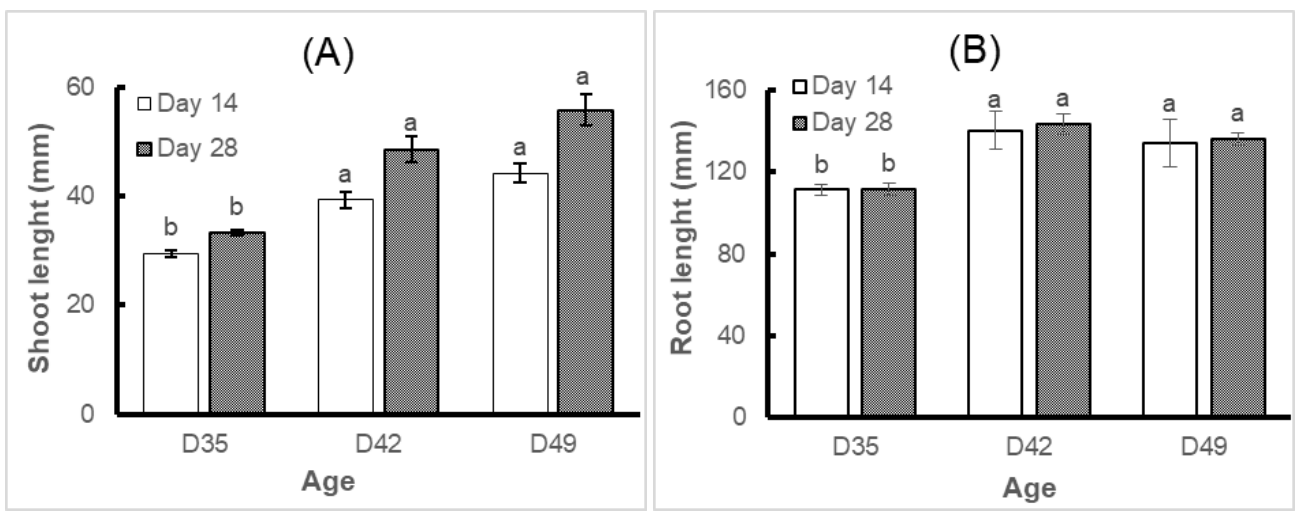

Figure 3. (A) Shoot length and (B) Root length of in vitro Plumbago plants 14 and 28 days after transplantation to the ex vitro condition in the nursery house

Notes: For the age codes, see Fig. 1; Error bars: SD. 
Similar to the weight increases in table 1 , on both day 14 and 28 after transplantation, shoot length and root length of Indian leadwort plants of ages D42 and D49 of in vitro culture were not significantly different from each other, but were both statistically higher than those of age D35 (Fig. 3). Shoot lengths of all three ages of in vitro plants increased over cultivation time in the nursery house (Fig. 3A). However, root lengths of all ages did not increase from day 14 to day 28 of ex vitro cultivation (Fig. $3 \mathrm{~B}$ ).

On both 14 and 28 days after ex vitro transplantation, shoot/root fresh weight ratios of D35 plants were significantly higher (3.2 and 6.9, respectively) than those of D42 (2.6 and 4.5, respectively) and D49 (2.5 and 4.4, respectively) plants (Fig. 4). Similarly, shoot/root dry weight ratios of D35 were significantly higher $(4.7$ and 7.3, respectively) than those of D42 (3.5 and 4.9, respectively) and D49 (3.7 and 5.1, respectively) plants (Fig. 4). This indicated imbalance between shoot and root growth of D35 plants. This imbalance became larger over cultivation time in the nursery house, with shoot/root fresh and dry weight ratios of D35 plants increased by 2.1 and 1.5 times, respectively, by 28 days of ex vitro cultivation compared to that of 14 days of cultivation. We suspected that this might be due to the effect of endogenous auxin and cytokinin produced by plants during their growth in the ex vitro stage. In fact, the auxin/cytokinin ratios of D35, D42 and D49 Plumbago plants after 28 days in ex vitro cultivation were $0.64,1.32$ and 1.30 , respectively, based on the bioassay measurements (Table 2). Higher auxin/cytokinin ratio will promote root formation, resulting in more balanced shoot and root growth.

Table 2. Relative activity of endogenous auxin (IAA) and cytokinin (zeatin) of in vitro Plumbago plants in the ex vitro cultivation measured by bioassays on day 28

\begin{tabular}{|c|c|c|c|}
\hline \multirow{2}{*}{ Age $^{\mathrm{z}}$} & \multicolumn{3}{|c|}{ Relative activity (mg/L) } \\
\cline { 2 - 4 } & Zeatin & IAA & Auxin/Cytokinin \\
\hline $\mathrm{D} 35$ & $0.19 \mathrm{a}^{\mathrm{x}}$ & 0.13 & $0.64 \mathrm{~b}$ \\
\hline $\mathrm{D} 42$ & $0.12 \mathrm{~b}$ & 0.16 & $1.32 \mathrm{a}$ \\
\hline D49 & $0.11 \mathrm{~b}$ & 0.14 & $1.30 \mathrm{a}$ \\
\hline ANOVA $^{\mathrm{y}}$ & $* * *$ & NS & $* *$ \\
\hline CV (\%) & 7.7 & 12.9 & 15.3 \\
\hline
\end{tabular}

Notes: ${ }^{\mathrm{z}}$ : For the age codes, see Fig. $1 ;{ }^{\mathrm{y}}$ : NS, ${ }^{*},{ }^{* *}$, or ${ }^{* * *}$ : Non-significant or significant at $\mathrm{p} \leq 0.05$, 0.01 , or 0.001 respectively; ${ }^{x}$ : Means in the same column followed by the same letters are not significantly different according to LSD-test.

Shoot/root weight ratio varies depending on plant age, water, nutrients and light availability, etc. The change in the environmental factors such as nutrients, light and $\mathrm{CO}_{2}$ can alter growth pattern of plants (Ericsson, 1995; Bonifas \& Lindquist, 2006). Plants respond to changes of environmental conditions by regulating the balance in nitrogen and carbon partitioning (Chen et al., 1993). The ratio between shoot and root weights can be altered corresponding to the carbon and nitrogen partitioning levels in root and shoot (Marcelis, 1996). Both fresh and dry shoot/root weight ratios of D42 and D49 plants were lower than those of D35 plants at 14 and 28 days after ex vitro transplantation (Fig. 4). This showed that the developments of roots of D42 and D49 were more robust than that of D35 plants. Indian leadwort plants of D42 and D49 in vitro plants had higher initial fresh weight as well as more leaves than did D35 plants, which translated into better carbon fixation and root formation after ex vitro cultivation. Consequently, these plants would adjust the absorption of nutrients from root to ensure a balanced growth, since 
photosynthetic rate is directly related to nitrogen content in leaves (Agren \& Ingestad,
1987; Hilbert, 1990; Levin et al., 1989; Lindquist, 2001).

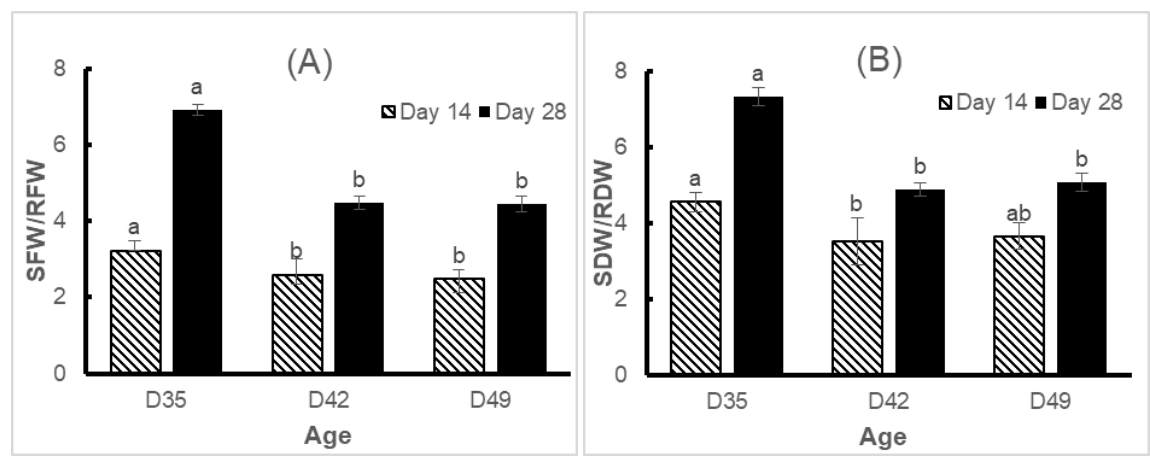

Figure 4. (A) Shoot fresh weight/Root fresh weight (SFW/RFW) and (B) Shoot dry weight/Root dry weight (SDW/RDW) of in vitro Plumbago plants in the ex vitro stage 14 and 28 days after transplantation in the nursery house.

Notes: For the age codes, see Fig. 1; Error bars: SD.

On day 28 after ex vitro transplantation, $\% \mathrm{DM}$ of Indian leadwort plants followed a similar trend as plant DW change, lowest in D35 plants (12.3\%) while comparable between in D42 and D49 plants (13 and $13.3 \%$, respectively) (Fig. 5). Plant growth is typically characterized by relative growth rate (RGR); however, RGR has a tendency to decline as plants become larger, and this makes it difficult to compare plant species of different sizes. Relative growth rate of Indian leadwort plants during 28 days of cultivation in the nursery house was not different statistically between D35 plants $\left(0.051 \mathrm{~d}^{-1}\right)$ and D42 plants $\left(0.053 \mathrm{~d}^{-1}\right)$, while that of D49 $\left(0.048 \mathrm{~d}^{-1}\right)$ was significantly lower than others (Fig. 5). According to Li et al. (2014), RGR is proportional to shoot weight, but inversely proportional to root weight, and also depending on plant age, water and nutrient availability and light intensity. In this series of experiments, Indian leadwort plants of D35 had shoot/root weight ratios higher than those of D49 plants (Fig. 4). Meanwhile, on day 28 after transplantation, even though shoot/root weight ratios of D42 plants were not different from those of D49 plants (Fig. 4), LA of D42 plants was greater than that of D49. This showed that thanks to higher RGRs, D35 and D42 plants distributed more carbohydrates into leaves for photosynthetic activity.

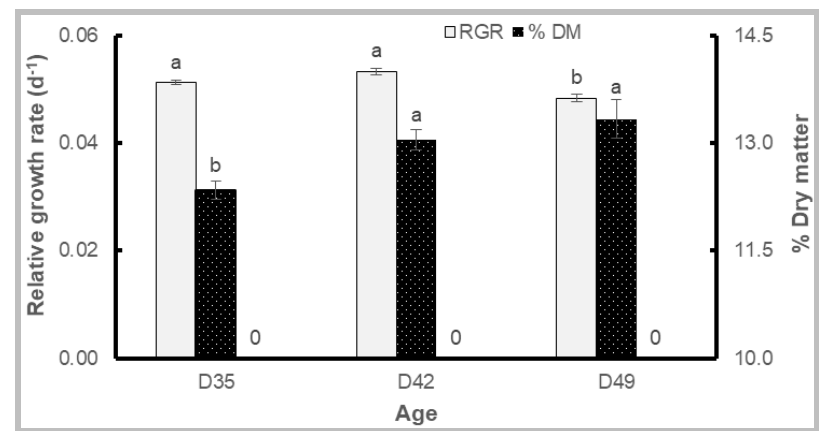

Figure 5. Relative growth rate $\left(\mathrm{RGR}, \mathrm{d}^{-1}\right)$, and percentage of dry matter $(\% \mathrm{DM})$ of in vitro Plumbago plants 28 days after ex vitro cultivation.

Notes: For the age codes, see Fig. 1; Error bars: SD. 
In summary, in vitro Indian leadwort plants at all ages (35, 42 and 49 day-old) could survive $100 \%$ after ex vitro transplantation without any acclimatization step. In vitro plants were able to adapt and develop when transferred to ex vitro condition at the in vitro culture age of 35 day-old. Older in vitro plants had faster growth when transplanted to ex vitro condition, but there was no significant difference in growth between in vitro plants of 42 and 49 days old. During the observation of 28 days in the nursery house, 42 day-old plants showed the best growth after transplanted to ex vitro condition.

Acknowledgements: This study received equipment and facility support from the National Key Laboratory of Plant cell technology, Institute of Tropical Biology, VAST, and technical support from Mrs. Trinh Thi Thanh Van, Department of Plant Cell Technology, Institute of Tropical Biology, VAST.

\section{REFERENCES}

Agren G. I., Ingestad T., 1987. Root:shoot ratio as a balance between nitrogen productivity and photosynthesis. Plant Cell Environ. 10: 579-586. https://doi.org/ 10.1111/1365-3040.ep11604105

Bhadra S. K., Akhter T., Hossain M. M., 2009. In vitro micropropagation of Plumbago indica $\mathrm{L}$. through induction of direct and indirect organogenesis. Plant Tissue Cult. \& Biotech. 19(2): 169 - 175. https://doi.org/10.3329/ptcb.v19i2.5434

Bolar J. P., Norelli J., Aldwinckle H.S., Hanke V., 1998. An efficient method for rooting and acclimatization of micropropagated apple culture. Hort. Sci. 37: 1241-1252. https://doi.org/10.21273/ HORTSCI.33.7.1251

Bonifas K. D., Lindquist J. L., 2006. Predicting biomass partitioning to root versus shoot in corn and velvetleaf (Abutilon theophrasti). Weed Sci., 54: 133-137. https://doi.org/10.1614/WS-05079R1.1
Chandra S., Bandopadhyay R., Kumar V., Chandra R., 2010. Acclimitization of tissue cultured plantlets: from laboratory to land. Biotech. Lett., 32: 1199-1205. https://doi.org/10.1007/s10529-010-0290-0

Chen J-L., Reynolds J. F., Harley P. C., Tenhunen J. D., 1993. Coordination theory of leaf nitrogen distribution in a canopy. Oecologia., 93: 63-69. https://doi.org/10.1007/BF00321192

Deb C. R, Imchen T., 2010. An efficient in vitro hardening of tissue culture raised plants. Biotechnology, 9: 79-83. https://doi.org/10.3923/biotech.2010.79.83

Donnelly D. J., Vidaver W. E., Lee K. Y., 1985. The anatomy of tissue cultured red raspberry prior to and after transfer to soil. Plant Cell Tiss. Org. Cult., 4: 43-50. https://doi.org/10.1007/BF00041654

Do B. H., Dang C. Q., Bui C. X., Nguyen D. T., Do D. T., Pham H. V., Vu L. N., Pham M. D., Pham M. K., Doan N. T., Nguyen T., Tran T., 2004. Chapter 31: Plumbago zeylanica L. pp. 148 - 150. In: Medicinal Plants and Animals in Vietnam. Science and Technology Publisher, Hanoi, Vietnam. Vol. 1 (in Vietnamese).

Ericsson T., 1996, Growth and shoot: root ratio of seedlings in relation to nutrient availability. Plant and Soil, 168-169: 205-214. https://doi.org/10.1007/97894-011-0455-5_23

Galal A M., Raman V., Avula B., Wang Y H., Rumalla C S., Weerasooriya A D., Khan I A., 2013. Comparative study of three Plumbago L. species (Plumbaginaceae) by microscopy, UPLC-UV and HPTLC. $J$. Nat. Med., 67(3): 554-561. https://doi.org/ 10.1007/s11418-012-0717-0

Hilbert D. W., 1990. Optimization of plant root: shoot ratios and internal nitrogen concentration. Ann. Bot. 66: 91-99. https://doi.org/10.1093/oxfordjournals.aob

Hoffmann W. A., Poorter H. IK., 2002. Avoiding bias in calculations of relative growth rate. Ann. Bot., 80: 37-42. https://doi.org/10.1093/aob/mcf140 
Jamal M. S., Parveen S., Beg M. A., Suhail M., Chaudhary A G A., Damanhouri G A., Abuzenadah A M., Rehan M., 2014. Anticancer compound Plumbagin and its molecular targets: A structural insight into the inhibitory mechanisms using computational approaches. Plos One. 9(2): 1-12. https://doi.org/10.1371/journal. pone.0087309

Jose B., Dhanya B P., Silja P. K., Krishnan P. N., Satheeshkumar K., 2014. Plumbago rosea L. - A review on tissue culture and pharmacological research. Int. J. Pharm. Sci. Rev. Res., 25(1): 246-256.

Levin S. A., Mooney H. A., Field C., 1989. The dependence of plant root : shoot ratios on internal nitrogen concentration. Ann. Bot., 64: 71-75. https://doi.org/10.1093/ oxfordjournals.aob.a087810

Li Y.Y., Lü X.T., Wang Z. W., Zhou C., Han X. G., 2014. Linking relative growth rates to biomass allocation: the responses of the grass Leymus chinensis to nitrogen addition. Phyton., 83: 283-289. https://doi.org/10.32604/phyton.2014.83.2 83

Lindquist J. L., 2001. Light-saturated CO2 assimilation rates of corn and velvetleaf in response to leaf nitrogen and development stage. Weed Sci., 49: 706-10. https://doi.org/10.1614/0043-1745(2001)0 49[0706:LSCARO]2.0.CO;2

Mallavadhani U V., Sahu G., Muralidhar J., 2002. Screening of Plumbago species for the bio-active marker plumbagin. Pharm. Biol., 40(7): 508-511. https://doi.org/ 10.1076/phbi.40.7.508.14685

Marcelis L. F. M., 1996. Sink strength as a determinant of dry matter partitioning in the whole plant. J. Exp. Bot., 47: 1281-1291.

Morel G., Wetmore R. H., 1951. Tissue culture of monocotyledons. Am. J. Bot., 38(2): $\quad 138-140 . \quad$ https://doi.org/ $10.2307 / 2437836$

Murashige T., Skoog F., 1962. A revised medium for rapid growth and bio-assays with tobacco tissue cultures. Physiol. Plant, 15(3): 473-497. https://doi.org/ 10.1111/j.13993054.1962.tb08052.x

Nguyen S. D., Phan H. N., 2013. Chapter 5: Extracted and identified active substances of plant growth regulators by bioassays in internship in plant physiology. Publishing House of HCM National, HCM City, Vietnam, pp. 57-66 (in Vietnamese).

Nguyen Q. T., Xiao Y, Kozai T., 2016. Photoautotrophic micropropagation. pp. 271-283. In: Kozai T., Niu G., Takagaki M. (eds.) Plant Factory - An indoor vertical farming system for efficient quality food production ( $1^{\text {st }}$ edition). Academic Press, Elsevier. California, USA. (ISBN: 978-0-12-801775-3). http://doi.org/10.1016/B978-0-12-8017753.00020-2

Panichayupakaranant P., Tewtrakul S., 2002. Plumbagin production by root cultures of Plumbago rosea. Electron. J. Biotech., 5(3): 228-232. https://doi.org/10.2225/ vol5-issue3-fulltext-4

Pant M., Lal A., Rana S., Rani A., 2012. Plumbago zeylanica L.: a Mini Review. Int. J. Pharm. Appl., 3(3): 399-405.

Pospíšilová J., Tichá I., Ek P K Č., Haisel D., 2007. Acclimation of plantlets to ex vitro conditions: Effects of air humidity, irradiance, $\mathrm{CO}_{2}$ concentration and abscisic acid (a review). Acta Hort., 42(96): 481497. https://doi.org/10.17660/ActaHortic. 2007.748.2

Priyanjani S. A., Senarath W. TPSK., 2019. Propagation of Plumbago indica L. (Plumbaginaceae) through direct organogenesis and induction of callus. Int J. Bot. Studies. 4(5): 4-7

Sumathy N., Sanjayan K.P., 2011. Effect of Plumbagin, a Napthoquinone of plant origin, on the consumption and post ingestional physiological parameters of food utilization in Spodoptera litura (Fab) (Lepidoptera: Noctuidae). GJAR, 1(2): 83-88. 
Weraduwage S. M., Chen J., Anozie F. C.,
Morales A., Weise S. E., Sharkey T. D., 2015. The relationship between leaf area growth and biomass accumulation in Arabidopsis thaliana, Front. Plant Sci, 6: 167. https://doi.org/10.3389/fpls.2015. 00167
Zakaria N. Y., Ismail M. R., Awang Y., Wahab P. E. M., Berahim Z., 2020. Effect of root restriction on the growth, photosynthesis rate, and source and sink relationship of chili (Capsicum annuum L.) grown in soilless culture. BioMed. Res. Int., Vol. 2020: 1-14. https://doi.org/ $10.1155 / 2020 / 2706937$ 